\title{
Infarctions in the vascular territory of the posterior cerebral artery: clinical features in 232 patients
}

\author{
Adrià Arboix ${ }^{1,2^{*}}$, Guillermo Arbe ${ }^{1}$, Luis García-Eroles ${ }^{3}$, Montserrat Oliveres $^{1}$, Olga Parra ${ }^{2,4}$ and Joan Massons ${ }^{1}$
}

\begin{abstract}
Background: Ischemic stroke caused by infarction in the territory of the posterior cerebral artery (PCA) has not been studied as extensively as infarctions in other vascular territories. This single centre, retrospective clinical study was conducted a) to describe salient characteristics of stroke patients with PCA infarction, b) to compare data of these patients with those with ischaemic stroke due to middle cerebral artery (MCA) and anterior cerebral artery (ACA) infarctions, and c) to identify predictors of PCA stroke.

Findings: A total of 232 patients with PCA stroke were included in the "Sagrat Cor Hospital of Barcelona Stroke Registry" during a period of 19 years (1986-2004). Data from stroke patients are entered in the stroke registry following a standardized protocol with 161 items regarding demographics, risk factors, clinical features, laboratory and neuroimaging data, complications and outcome. The characteristics of these 232 patients with PCA stroke were compared with those of the 1355 patients with MCA infarctions and 51 patients with ACA infarctions included in the registry.

Infarctions of the PCA accounted for $6.8 \%$ of all cases of stroke $(n=3808)$ and $9.6 \%$ of cerebral infarctions $(n=2704)$. Lacunar infarction was the most frequent stroke subtype (34.5\%) followed by atherothrombotic infarction (29.3\%) and cardioembolic infarction (21.6\%). In-hospital mortality was 3.9\% $(n=9)$. Forty-five patients (19.4\%) were symptom-free at hospital discharge. Hemianopia (odds ratio $[O R]=6.43)$, lacunar stroke subtype $(O R=2.18)$, symptom-free at discharge $(O R=1.92)$, limb weakness $(O R=0.10)$, speech disorders $(O R=0.33)$ and cardioembolism $(O R=0.65)$ were independent variables of PCA stroke in comparison with MCA infarction, whereas sensory deficit $(\mathrm{OR}=2.36)$, limb weakness $(\mathrm{OR}=0.11)$ and cardioembolism as stroke mechanism $(\mathrm{OR}=0.43)$ were independent variables associated with PCA stroke in comparison with ACA infarction.
\end{abstract}

Conclusions: Lacunar stroke is the main subtype of infarction occurring in the PCA territory. Several clinical features are more frequent in stroke patients with PCA infarction than in patients with ischaemic stroke due to infarction in the MCA and ACA territories. In-hospital mortality in patients with PCA territory is low.

\section{Background}

Knowledge of the clinical features of cerebral infarctions according to the affected vascular territory is important to characterize the diverse spectrum of symptoms associated with the vascular topography of lesions. Infarctions in the territory of the posterior cerebral artery (PCA) are not uncommon [1] but some aspects of the natural history of PCA infarction, such as aetiology, clinical features and outcome have not been sufficiently documented. In many studies, patients with PCA infarction are included in

\footnotetext{
* Correspondence: aarboix@hscor.com

'Unit of Cerebrovascular Diseases, Service of Neurology, Hospital Universitari del Sagrat Cor, Universitat de Barcelona, Barcelona, Spain Full list of author information is available at the end of the article
}

group of hemispheric cerebral infarction as a whole, independently of the different vascular topography of lesions [1-3]. Moreover, the differential clinical profile between ischaemic stroke caused by PCA infarctions, middle cerebral artery (MCA) infarctions and anterior cerebral artery (ACA) infarctions is poorly defined, probably because separate analysis of PCA stroke as an individual clinical entity is rarely performed.

This single centre, retrospective clinical study was conducted with the following aims: a) to describe salient characteristics of stroke patients with PCA infarction, b) to compare data of these patients with those with ischaemic stroke due to middle cerebral artery (MCA) and anterior
C Biomed Central 
cerebral artery (ACA) infarctions, and c) to identify predictors of PCA stroke.

\section{Methods}

The database of the "Sagrat Cor Hospital of Barcelona Stroke Registry" with data of 3808 acute stroke patients was searched for those with a diagnosis of ischaemic stroke caused by occlusion in the territory of the PCA who were admitted consecutively to the Department of Neurology of the Sagrat Cor Hospital (an acute-care 350bed teaching hospital in the city of Barcelona) between January 1986 and December 2004. Details of this on-going hospital-based stroke registry have been previously reported [4]. Classification of subtypes of stroke and definitions of vascular risk factors were those recommended by the Cerebrovascular Study Group of the Spanish Society of Neurology [5] and have been used in previous studies $[4,6,7]$.

The objective of this clinical study was to assess differential features in aetiology, risk factors, clinical findings and early outcome between patients with PCA stroke and those with MCA and PCA infarctions. To this purpose, All patients with ischaemic cerebral infarction $(n=2704)$ included in the database were selected. The region of the infarction was identified on computerized tomographic (CT) scans and/or magnetic resonance imaging (MRI) studies and then PCA $(n=232)$, ACA $(n=51)$ and MCA $(n=1355)$ topographies were chosen. These three vascular territories were defined according to previously published and validated maps of cerebral vascular territories [8] and used in other studies $[4,6,7,9]$. Cortical, deep (involving thalamus and/or midbrain), or cortical and deep distribution in PCA topography were recorded. PCA infarcts with coincident infarcts outside the PCA territory were excluded (PCA plus infarctions) were excluded. Therefore, the study population included only patients with isolated PCA infarctions.

All patients were admitted to the hospital within 48 hours of onset of symptoms. On admission, demographic characteristics; salient features of clinical and neurological examination and results of laboratory tests (blood cell count, biochemical profile, serum electrolytes, urinalysis); chest radiography; twelve-lead electrocardiography. In all patients, brain CT scans were performed within the first week of hospital admission. Patients with negative results had a second CT during their stay in hospital or were studied by MRI (45.7\%). Angio-MRI was obtained during hospitalisation in 33.3\% of patients, echo-Doppler of the supra-aortic trunks in $60 \%$, and arterial digital subtraction angiography in 9.8\%. Other investigations included echocardiography in $56 \%$ of patients and lumbar puncture in $2 \%$. The degree of clinical disability at discharge from the hospital was evaluated according to the Rankin scale until
1990 and with the modified Rankin scale (mRS) [10] from 1990 onwards. Causes of death were assesses according to the criteria of Silver et al. [11].

Prior to conducting the study, approval was obtained from the Ethical Committee of Clinical Research of Hospital Universitari Sagrat Cor. Consent was also obtained for the use of hospital data included in the Sagrat Cor Hospital of Barcelona Stroke Registry.

\section{Statistical analysis}

Demographic characteristics, risk factors, clinical events and outcome of PCA stroke patients and those with infarctions of the MCA and ACA territories were compared using the Student's $t$-test or the Mann-Whitney $U$ test for continuous variables and the chi-square $\left(\chi^{2}\right)$ test (with Yate's correction when necessary) for categorical variables. Statistical significance was set at $P<0.05$. Variables were subjected to multivariate analysis with a logistic regression procedure and forward stepwise selection if $P<$ 0.10 after univariate testing. The effect of variables on the presence of infarction caused by occlusion of the PCA versus infarcts of the MCA and the ACA was studied in two multiple regression models based on demographic, vascular risk factors, and clinical and neuroimaging variables, in which the absence (codified as 0 ) or presence (codified as 1) of PCA infarction was the dependent variable. The level of significance was set as 0.15 , and the tolerance level at 0.0001 . The maximum likelihood approach was used to estimate weights of the logistic parameters. Odds ratio and 95\% confidence intervals (CI) were calculated from the beta coefficients and standard errors. The hypothesis that the logistic model adequately fitted the data was tested by means of the goodness of fit $\chi^{2}$ test. The SPSS-PC+ and the BMDP computer programmes were used for statistical analyses.

\section{Findings}

The 232 patients PCA territory infarcts accounted for $6.1 \%$ of all cases of stroke $(n=3808)$ and $8.6 \%$ of cerebral infarction $(n=2704)$ included in the stroke registry. There were 128 men and 104 women with a mean (SD) age of 73.9 (11.9) years. Thirty-seven patients were 85 years or age or older. Vascular risk factors in a decreasing order of frequency included hypertension $(58.6 \%)$, diabetes mellitus (30.2\%), atrial fibrillation (26.7\%) and dyslipidemia (19.4\%). History of previous TIA was present in $12.9 \%$ of patients. Sudden onset of neurological deficit was recorded in $46.6 \%$ of cases. Sensory symptoms occurred in $51.3 \%$ of cases, hemianopia in $41.4 \%$, limb weakness in 38.8 and speech disturbances (dysarthria, aphasia) in $30.2 \%$. Memory disorders were recorded in $25 \%$. Cortical territory involvement accounted in $51 \%$, deep involvement in 35\% and involvement of both cortical and deep in $14 \%$. Stroke subtypes included lacunar 
infarct in $34.5 \%$, atherothrombotic infarction in $29.3 \%$, cardioembolic infarction in $21.6 \%$ of patients, infarct of unknown cause in $8.6 \%$ and infarction of unusual aetiology in $6 \%$.

Nine patients died during the hospital stay, with an inhospital mortality rate of $3.9 \%$. Causes of death included herniation of the brain in 3 , sudden death in 3 , pneumonia in 2 and septicaemia in 1 . The median length of hospitalization was 11 days (25th-75th percentile, 8-17 days). Forty-five patients (19.4\%) were symptom-free at the time of hospital discharge (mRS grade $0-1)$. Of the remaining 187 patients, $58.6 \%$ had moderate disability (mRS grade $2-3$ ), 17\% moderately severe disability (mRS grade 4 ) and $5 \%$ severe disability (mRS grade 5 ).

As shown in Table 1, sex male, diabetes mellitus, headache at the time of stroke onset, dizziness, sensory symptoms, hemianopia, ataxia, symptom free at discharge and lacunar etiology were more frequent in stroke patients with PCA infarction than in those with MCA infarction and mean age, age $>85$ years, atrial fibrillation, alcohol abuse, early seizures, speech disturbances, altered consciousness, limb weakness, and cardioembolic etiology were less frequent. On the other hand, headache at the time of stroke onset and sensory deficit were more frequent, and motor deficit and cardioembolism as the aetiology of stroke less frequent in patients with PCA infarction than in those with ACA infarction (Table 1).

In the multivariate analysis (Table 2), hemianopia (odds ratio $[\mathrm{OR}]=6.43,95 \% \mathrm{CI} 4.25-9.74)$, lacunar as stroke mechanism $(\mathrm{OR}=2.18,95 \% \mathrm{CI} 1.42-3.35)$, symptom-free at discharge $(\mathrm{OR}=1.92,95 \% \mathrm{CI} 1.22-3.02)$, limb weakness $(\mathrm{OR}=0.10,95 \% \mathrm{CI} 0.07-0.14)$, speech disorders $(\mathrm{OR}=$ $0.33,95 \%$ CI 0.24-0.47) and cardioembolism as stroke mechanism $(\mathrm{OR}=0.65,95 \% \mathrm{CI} 0.43-0.98)$ were independent variables of PCA stroke in comparison with MCA infarction, whereas sensory symptoms $(\mathrm{OR}=2.36,95 \% \mathrm{CI}$ 1.16-4.82), limb weakness $(\mathrm{OR}=0.11,95 \%$ CI 0.04-0.25) and cardioembolism as stroke mechanism $(\mathrm{OR}=0.43$, 95\% CI 0.21-0.85) were independent variables associated with PCA stroke as compared with ACA infarction.

\section{Discussion}

According to data of our hospital-based stroke registry, cerebral infarctions in the PCA territory is a subgroup of unusual cerebral infarcts, accounting for $6.1 \%$ of all cases of stroke and $8.6 \%$ of all cases of cerebral infarctions. There is limited data on the frequency of cerebral infarctions in the territory of the PCA in the different clinical studies are scarce. Previous series of PCA infarcts varied between 34 patients in the study of Kinkel et al. [12) and 205 patients in the study of Lee et al. [13]. As shown in Table the present series of 232 patients is the largest group so far reported in the literature (Table 3 ).
It should be noted that $15.9 \%$ of our patients were older than 85 years of age. This finding is consisted with results of other studies [14,15] and highlights the increasing prevalence and clinical relevance of first-ever stroke in the oldest old population segment of developed countries.

The aetiology of PCA infarctions is poorly defined in the literature, although in our study, the most frequent aetiopathogenic mechanism was lacunar in $34.5 \%$ of cases, followed by atherothrombosis in $29.3 \%$, and cardioembolism in $21.6 \%$. In $8.6 \%$ of the cases, the cause was unknown. The following criteria [5,16] were used to establish the lacunar origin of the infarction: (a) sudden or gradual onset of a focal neurological deficit lasting $>24 \mathrm{~h}$ of the type described in the common lacunar syndromes (pure motor hemiparesis, pure sensory stroke, sensorimotor stroke ataxia hemiparesis, dysarthria-clumsy hand, and atypical lacunar syndromes), (b) CT scans or brain MRI either normal or demonstrated only small, localized thalamic lesions with diameter smaller than $20 \mathrm{~mm}$ that seemed appropriate for the neurological deficits, and (c) absence of cortical ischaemia, cervical carotid stenosis (> 50\% diameter) or major source for cardioembolic stroke. Cardioembolic stroke was defined $[5,17]$ as a medium-to-large size cerebral infarction, usually of cortical topography in which in the absence of other aetiologies, some of the following emboligenous cardiac disorders are documented: atrial flutter or atrial fibrillation, intracardiac thrombus or tumour, rheumatic valve disease, mitral or aortic valve prosthesis, endocarditis, sinus node disease, left ventricular aneurysm after acute myocardial infarction, acute myocardial infarction in the acute phase (less than 3 months) or global cardiac hypokinesia.

This higher frequency of lacunar aetiology in PCA infarcts as compared with infarcts in the territory of the $\mathrm{ACM}(\mathrm{OR}=2.18)$ has not been previously documented, probably because not only the superficial PCA territory was considered in the analysis, but also the deep territory of thalamoperforating or thalamogeniculated penetrating arterioles, the occlusion of which causes subcortical lacunar infarcts of thalamic topography or mesencephalic involvement. These infarcts due to penetrating artery disease are usually included in the literature in the series of lacunar infarctions but are not specified in the series of infarctions of the PCA territory [18].

Cardioembolism as the aetiology of infarction was less frequent in PCA patients than in patients with ACM infarctions $(\mathrm{OR}=0.65)$. The identification of cardioembolism in $21.6 \%$ of cases is similar to percentages of $24 \%$ reported in the study of Pessin et al. [19] and 20\% in the study of Lee et al. [13] but clearly higher than $17 \%$ found in the study of Kumral et al. [20] and 18\% in the study of Milandre et al. [21], and lower than $41 \%$ found by Yamamoto et al. [18], $31 \%$ by Steinke et al. [22] and $35 \%$ by Servan et al. [23]. 
Table 1 Results of univariate analysis

\begin{tabular}{|c|c|c|c|c|c|}
\hline Variable & PCA & MCA & $\begin{array}{c}\text { PCA vs. MCA } \\
P \text { value }\end{array}$ & ACA & $\begin{array}{c}\text { PCA vs. ACA } \\
P \text { value }\end{array}$ \\
\hline Total patients & 232 & 1355 & & 51 & \\
\hline Sex, male & $128(55.2)$ & $635(46.9)$ & 0.019 & $27(52.9)$ & 0.445 \\
\hline Age, years, mean (SD) & 73.9 (11.9) & 76 (11.4) & 0.011 & $74.4(14.7)$ & 0.801 \\
\hline Age $\geq 85$ years & $37(15.9)$ & $302(22.3)$ & 0.029 & $11(21.6)$ & 0.219 \\
\hline \multicolumn{6}{|l|}{ Risk factors } \\
\hline Hypertension & $136(58.6)$ & $769(56.8)$ & 0.595 & $28(54.9)$ & 0.369 \\
\hline Diabetes & $70(30.2)$ & $301(22.2)$ & 0.008 & $15(29.4)$ & 0.530 \\
\hline Valvular Heart Disease & $16(6.9)$ & $95(7)$ & 0.950 & $1(2)$ & 0.153 \\
\hline Coronary heart disease & $36(15.5)$ & $223(16.5)$ & 0.720 & $4(7.8)$ & 0.111 \\
\hline Atrial fibrillation & $62(26.7)$ & $461(34)$ & 0.029 & $12(23.5)$ & 0.391 \\
\hline Cardiac heart failure & $9(3.9)$ & $88(6.5)$ & 0.124 & $4(7.8)$ & 0.190 \\
\hline Transient ischemic attack & $30(12.9)$ & $152(11.2)$ & 0.449 & $4(7.8)$ & 0.225 \\
\hline Previous cerebral infarct & $41(17.7)$ & $225(16.6)$ & 0.688 & $10(19.6)$ & 0.440 \\
\hline Previous hemorrhagic stroke & $4(1.7)$ & $10(0.7)$ & 0.138 & $1(2)$ & 0.633 \\
\hline Peripheral vascular disease & $13(5.6)$ & $100(7.4)$ & 0.331 & $2(3.9)$ & 0.472 \\
\hline Obesity & $11(4.7)$ & $51(3.8)$ & 0.478 & $4(7.8)$ & 0.276 \\
\hline Alcohol abuse & $1(0.4)$ & $39(2.9)$ & 0.028 & 0 & 0.820 \\
\hline Smoking (> 20 cigarettes/day) & $20(8.6)$ & $132(9.7)$ & 0.592 & $3(5.9)$ & 0.376 \\
\hline Hyperlipidemia & $45(19.4)$ & $226(16.7)$ & 0.309 & $9(17.6)$ & 0.474 \\
\hline \multicolumn{6}{|l|}{ Clinical findings } \\
\hline Sudden onset & $108(46.6)$ & $722(53.3)$ & 0.058 & $27(52.9)$ & 0.251 \\
\hline Headache & $53(22.8)$ & $120(8.9)$ & 0.000 & 0 & 0.000 \\
\hline Dizzines & $7(3)$ & $14(1)$ & 0.015 & $2(3.9)$ & 0.504 \\
\hline Early seazures & 0 & $24(1.8)$ & 0.041 & $1(2)$ & 0.180 \\
\hline Nausea, vomiting & $17(7.3)$ & $62(4.6)$ & 0.075 & $2(3.9)$ & 0.299 \\
\hline Aphasia and dysarthria & $70(30.2)$ & $816(60.2)$ & 0.000 & $22(43.1)$ & 0.054 \\
\hline Altered consciousness & $28(12.1)$ & $278(20.5)$ & 0.003 & $4(7.8)$ & 0.277 \\
\hline Limb weakness & $90(38.8)$ & $1145(84.5)$ & 0.000 & $44(86.3)$ & 0.000 \\
\hline Sensory symptoms & 119 (51.3) & $554(40.9)$ & 0.003 & $15(29.4)$ & 0.003 \\
\hline Hemianopsia & $96(41.4)$ & $264(19.5)$ & 0.000 & & \\
\hline Ataxia & $12(5.2)$ & $33(2.4)$ & 0.020 & & \\
\hline Stroke Subtypes & & & & & 0.001 \\
\hline Atherothrombotic & $68(29.3)$ & $395(29.2)$ & & $15(29.4)$ & \\
\hline Lacunar & $80(34.5)$ & $301(22.2)$ & & $6(11.8)$ & \\
\hline Cardioembolic & $50(21.6)$ & $482(35.6)$ & & $23(45.1)$ & \\
\hline Essential & $20(8.6)$ & $124(9.2)$ & & $6(11.8)$ & \\
\hline Unusual etiology & $14(6)$ & $52(3.9)$ & & $1(2)$ & \\
\hline Symptom-free at discharge & $45(19.4)$ & $149(11)$ & 0.000 & $5(9.8)$ & 0.072 \\
\hline Cardiac complications & $6(2.6)$ & $78(5.8)$ & 0.046 & $2(3.9)$ & 0.439 \\
\hline Infectious complications & $15(6.5)$ & $237(17.5)$ & 0.000 & $6(11.8)$ & 0.155 \\
\hline Respiratory complications & $12(5.2)$ & $176(13)$ & 0.001 & $4(7.8)$ & 0.321 \\
\hline Length of hospital stay, median (25th-75th percentile) & $11(8-17)$ & $13(9-23)$ & 0.003 & $12(10-24)$ & 0.345 \\
\hline In-hospital mortality & $9(3.9)$ & $235(17.3)$ & 0.000 & $4(7.8)$ & 0.190 \\
\hline
\end{tabular}

Data are $n(\%)$ unless otherwise stated.

Comparison of patients with posterior cerebral artery infarction (PCA) with patients with middle cerebral artery infarction (MCA) and patients with anterior cerebral artery infarction (ACA). 
Table 2 Results of multivariate analysis

\begin{tabular}{|c|c|c|c|c|}
\hline Variable & $\beta$ & SE ( $\beta)$ & $\begin{array}{l}\text { Odds ratio } \\
(95 \% \mathrm{Cl})\end{array}$ & $\begin{array}{c}P \\
\text { value }\end{array}$ \\
\hline \multicolumn{5}{|l|}{ PCA versus. MCA* } \\
\hline \multicolumn{5}{|c|}{ Model based on demographic, vascular risk, clinical, and topographic data* } \\
\hline Hemianopia & 1.861 & 0.212 & $6.43(4.25-9.74)$ & 0.000 \\
\hline Lacunar infarction & 0.780 & 0.219 & $2.18(1.42-3.35)$ & 0.000 \\
\hline Symptom-free at discharge & 0.653 & 0.230 & $1.92(1.22-3.02)$ & 0.005 \\
\hline Limb weakness & -2.322 & 0.176 & $0.10(0.07-0.14)$ & 0.000 \\
\hline Speech disorders (dysarthria) & -1.102 & 0.175 & $0.33(0.24-0.47)$ & 0.000 \\
\hline Cardioembolic infarction & -0.436 & 0.214 & $0.65(0.43-0.98)$ & 0.042 \\
\hline \multicolumn{5}{|l|}{ PCA versus $A C A$} \\
\hline \multicolumn{5}{|c|}{ Model based on demographic, vascular risk, clinical, and topographic data ${ }^{\dagger}$} \\
\hline Sensory symptoms & 0.8610 & 0.363 & $2.36(1.16-4.82)$ & 0.018 \\
\hline Limb weakness & -2.258 & 0.437 & $0.11(0.04-0.25)$ & 0.000 \\
\hline Cardioembolic stroke & -0.856 & 0.352 & $0.43(0.21-0.85)$ & 0.015 \\
\hline
\end{tabular}

In this respect, this aetiological aspect is important because a diagnosis of cardioembolism has practical implications in the management of these patients. In the presence of a cardioembolic infarction in the PCA territory, early anticoagulation at therapeutic doses as a secondary prevention of cardioembolic stroke should be indicated [24,25].

Patients with infarcts in the PCA territory have a relatively favourable short-term prognosis as shown by a higher frequency of symptom free at discharge (OR = 1.92) an in-hospital mortality rate of $3.9 \%$, clearly lower that $17.3 \%$ of MCA infarctions. In the series of Brandt et al. [26] and Cals et al. [27], none of the patients with acute PCA territory infarcts died. Other authors have reported similar mortality rates (3\% in the study of Yamamoto et al. [18]) or higher in-hospital mortality, such as $7 \%$ in the study of Milandre et al. [21], and 5\% in the study of Pessin et al. [19].

It should be noted that PCA infarcts present a clinical profile clearly different than the remaining cerebral hemispheric infarctions. Hemianopia $(\mathrm{OR}=6.43$ ) was independent variable associated with PCA infarctions as compared with MCA stroke. Initial neurological deficits are predominantly visual followed by sensory complaints [8]. The lower frequency of dysarthria or aphasia is explained because both Broca's motor speech area and sensory speech area of Wernicke are located in the vascular territory of the MCA $[1,8]$. The lower frequency of limb weakness $(\mathrm{OR}=0.10)$ is another clinical feature. Occurrence of motor deficits with PCA territory ischemia is considered unusual. Motor deficits was usually slight is due to oedema in the posterior limb of the internal capsule adjacent to the thalamus infarct with reversible impairment of pyramidal tracts. Hemiplegia in patients with PCA territory infarcts is usually caused by involvement of the cerebral peduncle [8].

Variables associated with PCA stroke $v s$. infarctions in the vascular territory of the ACA were sensory deficit, motor deficit, and cardioembolism. The higher frequency of sensory deficit in PCA stroke than in ACA infarction is explained because the deep vascular territory of the PCA includes the ventroposterolateral thalamic nucleus [28]. The frequency of motor deficit with a characteristic crural distribution is the most common neurological sign of ACA stroke and was present in $86.3 \%$ of our patients as compared with a prevalence of $93.3 \%$ in the series of Kumral et al. [29] and $96 \%$ in the experience of the Lausanne Stroke Registry [30]. Infarctions in the ACA territory usually involve the paracentral component of the frontal lobe affecting motor neurons with a somotatotopic distribution mostly related to the lower extremities [1].

There are no data on long-term outcome of PCA stroke. The recent study of Ntaios et al. [31] provides for the first time long-term follow-up data on prognosis in a large series of consecutive patients with infarctions in the PCA territory, showing that long-term mortality was associated with initial neurological severity (NIHSS score). This coincides with observations in the remaining ischaemic stroke subtypes in which motor weakness is an important clinical feature that causes greater focal neurological symptoms and is significantly associated with early death [10].

A recent study of intravenous thrombolysis in PCA infarcts has shown no substantial differences regarding baseline stroke severity, outcome, safety and clinical 
Table 3 Main series of cerebral infarcts in the territory of the posterior cerebral artery (PCA) reported in the literature

\begin{tabular}{|c|c|c|c|c|c|c|}
\hline $\begin{array}{l}\text { First author, } \\
\text { year [reference] }\end{array}$ & Patients & Most frequent clinical findings & Aetiology & $\begin{array}{c}\text { Frequency } \\
\text { total } \\
\text { infarcts }\end{array}$ & $\begin{array}{c}\text { Frequency } \\
\text { total } \\
\text { stroke } \\
\end{array}$ & $\begin{array}{c}\text { In- } \\
\text { hospital } \\
\text { mortality }\end{array}$ \\
\hline Kinkel, 1984 [12] & 34 & $\begin{array}{c}\text { Homonymous hemianopsia } 76 \% \text {, limb } \\
\text { weakness } 47 \%\end{array}$ & NA & NA & NA & NA \\
\hline Pessin, $1987[19]$ & $41^{*}$ & $\begin{array}{l}\text { Homonymous hemianopsia } 61 \% \text {, sensory } \\
\text { deficits } 20 \% \text {, limb weakness } 15 \%\end{array}$ & Unknown 27\%, cardioembolic $24 \%$ & NA & NA & $5 \%$ \\
\hline Servan, 1992 [23] & 76 & $\begin{array}{l}\text { Homonymous hemianopsia } 84 \% \text {, sensory } \\
\text { deficits } 32 \%\end{array}$ & Unknown 27\%, cardioembolic 35\% & NA & NA & NA \\
\hline $\begin{array}{l}\text { Bogousslavsky, } \\
1993[24]\end{array}$ & 70 & NA & $\begin{array}{c}\text { Large artery atherosclerosis } 66 \% \text {, } \\
\text { cardio- embolism } 21 \% \text {, small-artery } \\
\text { disease } 16 \%\end{array}$ & NA & NA & NA \\
\hline $\begin{array}{c}\text { Milandre, } 1994 \\
{[21]}\end{array}$ & 82 & $\begin{array}{l}\text { Homonymous hemianopsia } 43 \% \text {, sensory } \\
\text { deficits } 46 \% \text {, limb weakness } 34 \%\end{array}$ & Unknown 11\%, cardioembolic 18\% & NA & $4.2 \%$ & $7 \%$ \\
\hline Brandt, 1995 [26] & 127 & $\begin{array}{l}\text { Homonymous hemianopsia } 74 \% \text {, sensory } \\
\text { deficits 29\%, limb weakness } 28 \%\end{array}$ & Unknown 20\%, cardioembolic 28\% & NA & NA & $0 \%$ \\
\hline $\begin{array}{c}\text { Steinke, } 1997 \\
{[22]}\end{array}$ & $74^{*}$ & $\begin{array}{l}\text { Homonymous hemianopsia } 62 \% \text {, sensory } \\
\text { deficits } 15 \% \text {, limb weakness } 21 \%\end{array}$ & $\begin{array}{c}\text { Unknown } 24 \% \text {, intrinsic PCA disease } \\
30 \% \\
\text { cardioembolic } 31 \% \\
\end{array}$ & $1.3 \%$ & $1 \%$ & NA \\
\hline $\begin{array}{c}\text { Yamamoto, } 1999 \\
{[18]} \\
\end{array}$ & 79 & $\begin{array}{c}\text { Homonymous hemianopsia } 84 \% \text {, sensory } \\
\text { deficits 15\%, limb weakness 29\% }\end{array}$ & $\begin{array}{l}\text { Proximal arterial disease } 32 \% \\
\text { cardioembolism } 41 \%\end{array}$ & NA & NA & $3 \%$ \\
\hline Cals, 2002 [27] & $117^{*}$ & $\begin{array}{l}\text { Hemianopsia } 78 \% \text {, limb weakness } 12 \% \text {, } \\
\text { sensory deficits } 12 \%\end{array}$ & $\begin{array}{l}\text { Unknown 32\%, cardioembolism } \\
43.5 \%\end{array}$ & NA & $3.5 \%$ & $0 \%$ \\
\hline $\begin{array}{c}\text { Kumral, } 2004 \\
{[20]}\end{array}$ & 137 & & $\begin{array}{c}\text { Intrinsic PCA disease } 26 \% \text {, proximal } \\
\text { large } \\
\text { artery disease } 24 \% \text {, cardioembolism } \\
17 \%\end{array}$ & NA & NA & $7 \%$ \\
\hline Lee, 2009 [13] & 205 & & $\begin{array}{c}\text { Atherosclerosis } 42 \% \text {, cardioembolic } \\
20 \%\end{array}$ & NA & NA & NA \\
\hline Ntaios, 2011 [31] & 185 & & $\begin{array}{c}\text { Pure PCA }{ }^{\dagger} \text { : cardioembolism 39\%, } \\
\text { unknown } 22 \% \\
\text { PCA-plus }{ }^{\ddagger} \text { : cardioembolism } 63.4 \%\end{array}$ & $\begin{array}{l}8.1 \% \\
\text { NA }\end{array}$ & $\begin{array}{c}8.2 \% \\
25.4 \%\end{array}$ & NA \\
\hline $\begin{array}{l}\text { Present series, } \\
2011\end{array}$ & 232 & $\begin{array}{c}\text { Homonymous hemianopsia } 41 \% \text {, sensory } \\
\text { deficits } 51 \% \text {, limb weakness 39\% }\end{array}$ & $\begin{array}{c}\text { Lacunar } 34.5 \% \text {, atherosclerosis } 29.3 \% \\
\text { cardioembolism } 21.6 \%\end{array}$ & $8.6 \%$ & $6.1 \%$ & $3.9 \%$ \\
\hline
\end{tabular}

*Pure superficial PCA territory infarction.

${ }^{\dagger}$ Pure PCA: cortical or cortical and deep PCA infarcts.

₹ PCA-plus: cortical or cortical and deep infarcts coincident with infarct(s) outside the PCA territory -posterior or anterior circulation.

NA: not applicable.

findings between supratentorial PCA infarct patients and all patients with acute ischaemic stroke which would implicate a change in the existing thrombolysis practice in patients with PCA stroke [32].

Finally, a limitation of the study is related to the fact that not all patients underwent angio MR or CT angiogram to exclude the possibility of PCA stenosis, so that some of the patients with lacunar infarctions may in fact have PCA stenosis, and in these circumstances in the narrow sense, may be considered as atherotrhrombotic infarcts or infarcts of unknown cause by the presence of a double etiological mechanism: lacunar and atherotrhrombotic.

\section{Conclusions}

Cerebral infarcts in the PCA territory are infrequent and account for only $6.1 \%$ of all cases of cerebral infarction and $8.6 \%$ of all cases of stroke. Lacunar infarction is the main aetiological ischaemic subtype of PCA stroke. Patients with PCA infraction have a favourable shortterm prognosis. In-hospital mortality in patients with PCA territory is low and shows a clinical profile different than the remaining cerebral hemispheric infarcts.

\section{Abbreviations}

ACA: anterior cerebral artery; Cl: Confidence interval; $C \mathrm{~T}$ : Computed tomography; MCA: middle cerebral artery; MRI: Magnetic resonance imaging; OR: Odds ratio; PCA: Posterior cerebral artery; ROC: Receiver operating characteristics; SD: standard deviation; TIA: Transient ischaemic attack.

\section{Acknowledgements}

The study was supported by a grant from FIS PI081514, Madrid, Spain. We thank Adela Vicens, MD, Josep Maria Vives, MD, Noemí Amorós, MD and Anna Cartanyà, MD, for their valuable collaboration in the collection of data from the stroke registry, and Marta Pulido, MD., freelance author's editor, for editing the manuscript and editorial assistance. 


\section{Author details}

'Unit of Cerebrovascular Diseases, Service of Neurology, Hospital Universitari del Sagrat Cor, Universitat de Barcelona, Barcelona, Spain. ${ }^{2} \mathrm{CIBER}$ de Enfermedades Respiratorias (CB06/06), Instituto Carlos III, Madrid, Spain. ${ }^{3}$ Unit of Organization, Planning and Information Systems, Consorci Sanitari del Maresme, Barcelona, Spain. ${ }^{4}$ Service of Pneumology, Hospital Universitari del Sagrat Cor, Universitat de Barcelona, Barcelona, Spain.

\section{Authors' contributions}

AA was the principal investigator, designed the study, diagnosed and took care of the patients, contributed to analyze the data, interpreted the results, wrote the paper, and prepared the final draft. He was also responsible for editorial decisions including the selection of the journal GA, MO, OP and JM participated in the collection of data medical care of the patients, analysis of results, and review of the manuscript for intellectual content. LGE was the statistician, participated in the study design, analysis and interpretation of data, and wrote the part of the paper related to the statistical analysis. All authors read and approved the final manuscript.

\section{Competing interests}

The authors declare that they have no competing interests.

Received: 28 April 2011 Accepted: 7 September 2011

Published: 7 September 2011

\section{References}

1. Warlow C, van Gijn J, Dennis M, Wardlaw J, Bamford J, Hankey P, Rinkel G, Langhorne P, Sudlow C, Rothwell P: Which arterial territory is involved? Stroke Practical Management. Third edition. Oxford, UK: Blackwell Publishing, Ltd; 2008, 131-180.

2. Carrera E, Maeder-Ingvar M, Rossetti AO, Devuyst G, Bogousslavsky J: Trends in risk factors, patterns and causes in hospitalized strokes over 25 years: The Lausanne Stroke Registry. Cerebrovasc Dis 2007, 24:97-103.

3. Ghandehari K, Izadi Z: The Khorasan Stroke Registry: results of five-year hospital-based study. Cerebrovasc Dis 2007, 23:132-139.

4. Arboix A, Cendrós V, Besa M, García-Eroles L, Oliveres M, Targa C, Balcells M, Comes $E$, Massons J: Trends in risk factors, stroke subtypes and outcome. Nineteen-year data from the Sagrat Cor Hospital of Barcelona Stroke Registry. Cerebrovasc Dis 2008, 26:509-516.

5. Arboix A, Alvarez-Sabín J, Soler L, for the Cerebrovascular Study Group of the Spanish Society of Neurology: Nomenclatura de las enfermedades vasculares cerebrales. Neurologia 1998, 13(Suppl 1):1-10.

6. Marrugat J, Arboix A, García-Eroles L, Salas T, Vila J, Castell C, Tresserras R, Elosua R: The estimated incidence and case fatality rate of ischemic and hemorrhagic cerebrovascular disease in 2002 in Catalonia. Rev Esp Cardiol 2007, 60:573-580

7. Arboix A, Tarruella M, García-Erols L, Olivers M, Miquel C, Balcells M, Targa C: Ischemic stroke in patients with intermittent claudication: a clinical strudy of 142 cases. Vasc Med 2004, 9:13-17.

8. Brandt T, Steinke W, Thie A, Pessin MS, Caplan LR: Posterior cerebral artery territory infarcts: clinical features, infarct topography, causes and outcome. Multicenter results and review of the literature. Cerebrovasc Dis 2000, 10:170-182.

9. Arboix A, García-Eroles L, Sellarés N, Raga A, Oliveres M, Massons J: Infarction in the territory on the anterior cerebral artery: clinical study of 51 patients. BMC Neurol 2009, 9:30.

10. van Swieten JC, Koudstaal PJ, Visser MC, Schouten HJ, van Gijn J: Interobserver agreement for the assessment of handicap in stroke patients. Stroke 1988, 19:604-607.

11. Silver FL, Norris JW, Lewis AJ, Hachinski VC: Early mortality following stroke: a prospective review. Stroke 1984, 15:492-496.

12. Kinkel WR, Newmann RP, Lawrence J: Posterior cerebral artery branch occlusions: CT and anatomic considerations. In Vertebrobasilar Arterial Occlusive Disease. Edited by: Berguer R, Bauer RB. New York, NY: Raven Press; 1984:117-133.

13. Lee E, Kang DW, Kwon SU, Kim JS: Posterior cerebral artery infarction: diffusion-weighted MRI analysis of 205 patients. Cerebrovasc Dis 2009, 28:298-305.

14. Arboix A: Increasing relevance of acute cerebrovascular disease in very old patients. Eur J Neurol 2007, 14:833-834.
15. Rojas Jl, Zurrú MC, Romano M, Patrucco L, Cristiano E: Acute ischemic stroke and transient ischemic attack in the very old. Risk factors and stroke subtype between patients older than 80 years and patients aged less than 80 years. Eur I Neurol 2007, 14:895-899.

16. Arboix A, Martí-Vilalta JL: Lacunar stroke. Expert Rev Neurother 2009, 9:179-196.

17. Pujadas R, Arboix A, Casañas-Muñoz R, Anguera-Ferrando N: Specific cardiac disorders in 402 consecutive patients with ischaemic cardioembolic stroke. Int J Cardiol 2004, 95:129-134.

18. Yamamoto Y, Georgiadis AL, Chang HM, Caplan LR: Posterior cerebral artery territory infarcts in the New England Medical Center Posterior Circulation Registry. Arch Neurol 1999, 56:824-832.

19. Pessin MS, Lathi ES, Cohen MB, Kwan ES, Hedges TR, Caplan LR: Clinical features and mechanism of occipital infarction. Ann Neurol 1987, 21:290-299.

20. Kumral E, Bayulkem G, Ataç C, Alper Y: Spectrum of superficial posterior cerebral artery territory infarcts. Eur J Neurol 2004, 11:237-246.

21. Milandre L, Brosset C, Botti G, Khalil R: A study of 82 cerebral infarctions in the area of posterior cerebral arteries. Rev Neurol (Paris) 1994, 150:133-141.

22. Steinke W, Mangold J, Schwartz A, Hennerici M: Mechanisms of infarction in the superficial posterior cerebral artery territory. J Neurol 1997, 244:571-578.

23. Servan J, Catala M, Rancurel G: Posterior cerebral artery infarction: a study of 76 cases (Abstract). Cerebrovasc Dis 1992, 2:233.

24. Bogousslavsky J, Regli F, Maeder P, Meuli R, Neder J: The etiology of posterior circulation infarcts: a prospective study using magnetic resonance imaging and magnetic resonance angiography. Neurology 1993, 43:1528-1533.

25. Hart RG: Cardiogenic embolism to the brain. Lancet 1992, 339:589-594.

26. Brandt T, Thie A, Caplan LR, Hacke W: Infarkte im versorgungsgebiet der A. cerebri posterior. Nervenarzt 1995, 66:267-274.

27. Cals N, Devuyst G, Afsar N, Karapanayiotides T, Bogousslavsky J: Pure superficial posterior cerebral artery territory infarction in the Lausanne Stroke Registry. I Neurol 2002, 249:855-861.

28. Fisher CM: Thalamic pure sensory stroke: a pathologic study. Neurology 1978, 28:1141-1144.

29. Kumral E, Bayulkem G, Evyapan D, Yunten N: Spectrum of anterior cerebral artery territory infarction: clinical and MRI findings. Eur J Neurol 2002, 9:615-624.

30. Bogousslavsky J, Regli F: Anterior cerebral artery territory infarction in the Lausanne Stroke Registry. Clinical and etiologic patterns. Arch Neurol 1990, 47:144-150.

31. Ntaios G, Spengos K, Vemmou AM, Savvari P, Koromboki E, Stranjalis G, Vemmos K: Long-term outcome in posterior cerebral artery stroke. Eur J Neurol 2011.

32. Breuer $L$, Huttner HB, Jentsch $K$, Blinzler C, Winder $K$, Engelhorn $T$, Köhrmann M: Intravenous thrombolysis in posterior cerebral artery infarctions. Cerebrovasc Dis 2011, 31:448-454.

doi:10.1186/1756-0500-4-329

Cite this article as: Arboix et al: Infarctions in the vascular territory of the posterior cerebral artery: clinical features in 232 patients. BMC Research Notes 2011 4:329.

\section{Submit your next manuscript to BioMed Central and take full advantage of:}

- Convenient online submission

- Thorough peer review

- No space constraints or color figure charges

- Immediate publication on acceptance

- Inclusion in PubMed, CAS, Scopus and Google Scholar

- Research which is freely available for redistribution 